\title{
O Cloze como Técnica de Diagnóstico e Remediação da Compreensão em Leitura
}

\author{
Acácia Aparecida Angeli dos Santos \\ Universidade de São Francisco
}

\begin{abstract}
RESUMO
O objetivo deste estudo foi o de avaliar a eficácia da técnica de Cloze como instrumento de diagnóstico e de desenvolvimento da compreensão em leitura. Participaram 24 alunos de $5^{\text {a }}$ série de uma escola pública do interior de São Paulo. Do total, 11 eram do gênero masculino (45,8\%) e 13 do feminino $(54,2 \%)$. A média de idade foi de 11,8 anos $(D P=0,74)$. A coleta de dados ocorreu em situação de sala de aula e envolveu a aplicação de pré e pós-teste e um programa de intervenção com o uso do Cloze gradual em textos retirados de livros didáticos, apropriados para o nível de escolaridade dos participantes. A comparação dos resultados do pré e pós-testes apontou para uma diferença significativa, demonstrando que o Cloze parece adequado para o desenvolvimento da compreensão em leitura. Sugere-se que estudos similares sejam desenvolvidos em outras séries e outros tipos de escola para que novas evidências contribuam para a generalização dos resultados.
\end{abstract}

Palavras-chave: compreensão em leitura; ensino fundamental; avaliação educacional.

\section{ABSTRACT \\ The Cloze as a Technique of Assessment and Remediation of Reading Comprehension}

The objective of this study has been to evaluate the effectiveness of the Cloze Technique as an instrument for assessment and development of reading comprehension. For this purpose, we had the participation of 24 students of the $5^{\text {th }}$ series, consisting of $11(45,8 \%)$ boys and $13(54,2 \%)$ girls, from a government school of the interior of São Paulo State. Their average age was 11,8 years old $(S D=0,74)$. Data collecting took place in a classroom environment and involved the application of pre and posttests and an intervention program with the use of Cloze's gradual technique in texts extracted from didactical books appropriate for the school level of the participants. A comparison of pre and posttests results pointed out a significant difference, yet demonstrating that Cloze's program seems adequate for the development of comprehension in reading. It is suggested that similar studies be developed in other school grades, as well as other kinds of school, so that new evidence may contribute to a generalization of the results.

Keywords: reading comprehension; basic school; educacional evaluation.

A deficiência em compreensão em leitura tem sido apontada como um dos principais obstáculos para a efetivação do processo de ensino-aprendizagem. Inúmeras pesquisas têm demonstrado a importância da compreensão em leitura para um desempenho escolar bem sucedido (Braga, 1981; Muth, 1989; Santos, 1990; Olson, 1990; Santos, Suehiro \& Oliveira, 2004).

Alguns aspectos relacionados ao texto têm sido apontados como fatores que interferem na sua compreensão e comprometem o desempenho escolar. Entre eles, os mais freqüentes são o uso de palavras incomuns, o número de sílabas utilizadas, o tamanho das sentenças, a presença de categorias gramaticais mais difíceis, a complexidade da estrutura gramatical e a complexidade das idéias nele contidas (Molina, 1979; Mello, 1986; Abraham \& Chapelle, 1992).

Vários autores chamam a atenção para as características dos leitores que seriam dificultadoras da com- preensão da leitura. Entre elas, destacam-se as falhas no processo de decodificação, as carências de vocabulário, leitura oral pobre, deficiência de integração das informações e de memória, falta de estratégias de aprendizagem adequadas (Galinkoff, 1975-76; Boruchovitch, 1999).

Outro aspecto relevante que tem sido ressaltado refere-se à falta de motivação para a leitura, outra característica freqüentemente associada aos maus leitores. Verifica-se que um círculo vicioso é estabelecido, visto que aqueles que têm dificuldade para ler evitam as situações de leitura. Dessa forma, não conseguem obter a prática necessária para ler fluentemente, o que leva à diminuição da motivação e à relutância para a leitura. Tal situação ocorre em todos os níveis de escolarização (Viessi, 1979; Pellegrini, Santos \& Sisto, 2002, entre outros). 
Estudos estrangeiros têm demonstrado que a escola não tem atuado como fonte de incentivo para o desenvolvimento adequado do comportamento de ler. Nesse sentido Manna e Misheff (1987) realizaram uma pesquisa bastante ilustrativa sobre a questão. Realizaram a coleta de mais de mil autobiografias de pessoas que estavam realizando pós-graduação na área de leitura, visando verificar quais os determinantes de seu interesse pela área. A análise dos depoimentos indicou que as experiências positivas referentes à leitura estão associadas com atividades realizadas fora do âmbito escolar.

No Brasil a situação também não é diferente e os estudiosos da área têm chamado a atenção para o pouco que a escola contribui para o desenvolvimento do interesse pela leitura, bem como para a formação do leitor. Na maioria das vezes, a leitura feita na escola é utilizada apenas como recurso para o ensino gramatical e o treino ortográfico, predominando o distanciamento de tais práticas com o contexto da vida do aluno (Silva, 1983; Matos, 2001; Di Nucci, 2002).

O sucesso na aprendizagem da leitura e da escrita, bem como a posterior autonomia na leitura tem sido associada à interação dos pais com a escola e, especialmente, com o envolvimento deles nas práticas cotidianas de letramento. Particularmente a leitura de histórias infantis pelos pais tem se mostrado como um evento relevante para o interesse da criança por atividades de leitura e ao sucesso escolar (Leichter, 1984; Morrow, 1995; Santos \& Joly, 1996; Di Nucci, 1997; Corrêa, 2001).

No entanto, o que se observa é que as crianças passam pela escola sem ganhar o necessário domínio da leitura. Considerando que a escola é a instituição formalmente incumbida de fornecer às pessoas o acesso às diferentes fontes de informação, garantindo-lhes o necessário crescimento intelectual e experiencial, é lamentável verificar-se que tal papel não vem sendo adequadamente cumprido. Assim, a busca de soluções alternativas que melhorem a qualidade do ensino ministrado nas escolas é urgente e deve ser direcionada para a conciliação das práticas educativas vigentes com as mais recentes contribuições da ciência, com o aproveitamento de recursos que podem ser facilmente utilizados pelos professores e que sejam economicamente acessíveis.

Nessa direção, o procedimento de Cloze tem se destacado pela sua utilidade tanto para o diagnóstico como para o desenvolvimento da compreensão em leitura. Além de unir os aspectos de praticidade e economia de tempo e recursos, várias pesquisas têm demonstrado sua eficácia no alcance dos objetivos pretendidos, como referido na literatura a seguir.

\section{O Cloze como técnica de diagnóstico e desenvolvimento da compreensão em leitura}

Tal como proposto por Taylor em 1953, o Cloze consiste na organização de um texto, do qual se suprimem alguns vocábulos e se pede ao leitor que preencha os espaços com as palavras que melhor completarem o sentido do texto. A preparação do texto de Cloze segue regras que variam em função do objetivo para o qual ele será utilizado. Mais frequientemente são usados como parâmetros a omissão sistemática de palavras num sistema de razão, por ex. todo $5^{\circ}, 7^{\circ}$ ou $10^{\circ}$ vocábulo, a supressão de uma dada categoria gramatical (adjetivos, substantivos, verbos, entre outras) ou ainda a omissão aleatória de $20 \%$ dos vocábulos do texto (Bormuth, 1968; Hines \& Warren, 1978; Grant, 1979; Porter, 1979; Braga, 1981; Santos, 1981; Ashby-Davis, 1985; Giordano, 1985; Helfeldt \& Henk, 1985; Riley, 1986).

A maioria dos estudos se vale de uma dessas regras, dentre outras, para a organização do texto de Cloze, havendo também diferenças em relação a sua apresentação. Geralmente é apresentado por escrito, sendo a palavra suprimida substituída por um traço, que poderá ser de tamanho sempre igual, tal como proposto inicialmente por Taylor (1953), ou ainda por um traço proporcional ao tamanho da palavra omitida, como sugerido por Bormuth (1968), justificando que dessa forma os resultados obtidos apresentariam um índice mais alto de correlação com outras medidas de compreensão em leitura.

Desde que foi introduzido, o procedimento de Cloze tem sido utilizado como material em pesquisas diversas. Assim, pesquisadores da área têm recorrido a esse instrumento para avaliar a influência da posição sintática das palavras na sentença, bem como o valor do conhecimento prévio na compreensão oral e escrita. Ao lado disso, pesquisas sobre a legibilidade de textos e suas características lingüísticas tem sido objeto de interesse dos estudiosos do tema (Hines \& Warren, 1978; Witter, 1978; Molina, 1979, Bitar, 1989; Kobayashi, 2002).

Marini (1980) considera que o emprego do Cloze como técnica de desenvolvimento da habilidade de leitura está pautado na visão da compreensão como um processo que exige a interação entre o leitor e o escritor do texto, na forma de um contrato implícito entre o esforço do autor para se comunicar e o do leitor em entender a mensagem. Essa natureza interativa do processo de compreensão salienta a importância das pistas gramaticais e semânticas do texto, bem como dos padrões de linguagem e do conhecimento prévio sobre o assunto. Assim, o Cloze, como tarefa que envolve tanto as expectativas do leitor como as 
pistas do texto, tem sido visto como um instrumento apropriado para a avaliação e o desenvolvimento da compreensão em leitura.

Alguns autores ressaltam também que por meio dos exercícios com o Cloze pode-se dinamizar o processo de compreensão e obter melhor aprendizagem. As inúmeras possibilidades de variações da técnica permitem seu emprego em diferentes conteúdos e para alcançar diferentes objetivos. A supressão de categorias específicas de informação do texto pode ser realizada em função da finalidade pretendida pelo professor ou em função das dificuldades dos alunos. De qualquer modo reconhece-se que é um material de fácil elaboração e correção, o que o torna acessível e funcional como prática pedagógica (Giordano, 1985; Bitar, 1989).

O emprego do procedimento de Cloze facilita o ensino da leitura, atendendo alguns dos princípios considerados relevantes para que a verdadeira compreensão ocorra. Considera-se que o procedimento possibilita o desenvolvimento de algumas habilidades que favorecem o processo de compreensão, tais como: (a) estabelecer relações entre os elementos do texto; (b) estabelecer associações entre o conhecimento prévio e as informações impressas e (c) reconhecer quando o texto é ou não compreendido (Grant, 1979; Riley, 1986; Neves, 1997; Söhnhen, 1998; Sasaki, 2000).

Análises sobre o Cloze permitem afirmar que ele é mais que um instrumento de avaliação da leitura, pois em várias de suas formas ele possibilita a avaliação também da escrita. Tal fato é visto como um aspecto favorável, em razão da estreita relação entre os processos de leitura e escrita (Ashby-Davis, 1985; Poersch, 1993; Zucoloto, 2001). Mesmo sendo um instrumento particularmente atraente para uso em sala de aula, alguns cuidados mínimos devem ser tomados, pois sua construção de forma indiscriminada pode acarretar sérios erros de avaliação (Porter, 1979; Bitar, 1989; Oliveira, 1999).

Grant (1979) resume as idéias principais e algumas recomendações emanadas dos estudos realizados com o Cloze como técnica de desenvolvimento da compreensão em leitura. Tais recomendações são válidas especialmente quando se considera seu uso como uma das práticas pedagógicas em sala de aula, tal como sugerido a seguir: (a) iniciar com material elaborado com itens de múltipla escolha, preferencialmente com duas alternativas, que podem ser gradualmente aumentadas e posteriormente retiradas para que o leitor forneça a palavra que julgar mais adequada; (b) instruir o aluno a ler silenciosamente o texto todo antes de começar a preenchê-lo; (c) discutir com os alunos o processo de escolha da alternativa adequada, fazendo com que aprenda a delimitar as opções possíveis com o uso das pistas contidas no próprio texto ou relacionando-o com conhecimentos anteriores; (d) aceitar sinônimos, pois nem sempre o aluno vai responder com a palavra exata omitida do texto; (e) fornecer oportunidade imediata de autocorreção para que o aluno tenha o feedback do seu desempenho, comparando o texto original completo pelo produzido por ele.

Segundo Grant (1979) os resultados obtidos com o uso sistemático do Cloze como técnica de desenvolvimento da compreensão em leitura podem ser significativos e duradouros. No Brasil vários trabalhos de pesquisa com o uso da técnica têm sido relatados, com resultados bastante elucidativos, como os descritos a seguir.

Santos (1981) trabalhou com oito adolescentes institucionalizados com dificuldades escolares que freqüentavam o ensino fundamental, com o emprego da técnica de Cloze num programa de remediação em leitura. Os participantes apresentaram um aumento acentuado dos percentuais de acerto no pós-teste quando comparados aos resultados do pré-teste.

O estudo desenvolvido por Carelli (1992) objetivou testar a eficiência de programas de remediação e de desenvolvimento da criticidade na leitura. Os sujeitos foram 14 alunos de $5^{\text {a }}$ serie. Após dez sessões de aplicação do programa a autora detectou diferenças estatisticamente significativas nos resultados dos pósteste aplicados em ambos os grupos, havendo melhoras nos indicadores de criticidade, bem como na leitura geral dos sujeitos.

Para descrever o processo de aquisição e desenvolvimento de leitura, Castelo Branco (1992) desenvolveu um estudo com 40 alunos da $1^{\text {a }}$ a $4^{\text {a }}$ série do ensino fundamental. Valeu-se de provas de leitura oral e testes de Cloze para avaliar compreensão de leitura e produção de textos escritos com tema livre e à vista de uma gravura. Os resultados sugerem que o desempenho em leitura pode estar relacionado à facilidade para o reconhecimento de palavras, à melhor utilização da informação gráfica, com o uso do conhecimento fonológico, do conhecimento ortográfico e do vocabulário visual, adquiridos com a prática de leitura, e a utilização eficiente das informações contextuais.

Neves (1997) investigou o processamento da leitura em língua materna, com estudantes de sétima série de duas escolas públicas. As bases teóricas foram encontradas na lingüística textual, nas teorias de cognição e no processamento da informação. Objetivou verificar como o leitor organiza os seus conhecimentos para interagir com o texto. Aplicou duas baterias de testes, sendo a primeira bateria com testes de múltipla escolha e a segunda com uma adaptação da téc- 
nica de Cloze. Foram utilizados também textos de jornais e revistas como charge, propaganda, crônica, texto informativo e opinativo. Os resultados mostraram que, para a compreensão do texto, o aluno-leitor emprega o seu conhecimento prévio de forma quase sempre inadequada. Ao mesmo tempo constatou que os alunos lêem de forma fragmentada, com prejuízo para a significação do texto, apresentando muitos problemas para a compreensão das ambigüidades lingüísticas e semânticas. Uma das implicações pedagógicas refere-se à necessidade de um melhor preparo teórico e prático dos professores, visando a melhoria do ensino de leitura.

Com o objetivo de verificar os efeitos sobre a criatividade verbal, compreensão em leitura e criatividade na escrita dos alunos, Bampi (2000) aplicou um programa de desenvolvimento da criatividade aplicada à leitura e escrita. Foram sujeitos 42 alunos de $5^{\mathrm{a}}$ série, divididos em dois grupos experimentais (o primeiro submetido ao treino de criatividade e o outro a jogos psicodramáticos) e um de controle. Os materiais utilizados foram um teste de criatividade, o teste de Cloze e uma redação. Todos foram submetidos a um préteste, treinos específicos e pós-teste. Após as 15 sessões dos grupos experimentais, os resultados apontaram para um acréscimo significativo em flexibilidade de idéias, não havendo alterações nas demais habilidades de criatividade verbal. Pode-se dizer que as intervenções de treino nos grupos experimentais apresentam evidências de melhoria na escrita, em especial na categoria criativa "flexibilidade de idéias". No entanto, em relação à compreensão em leitura, as médias se mantiveram constantes.

A maioria dos estudos com a técnica de Cloze tem apresentado resultados satisfatórios, apontando seu uso como alternativa viável para o desenvolvimento da compreensão em leitura. Assim, detecta-se a necessidade de pesquisas que explorem as alternativas de diagnóstico e de desenvolvimento da leitura como prática pedagógica que possa ser utilizada por professores, especialmente em momentos críticos de mudanças de etapas de escolarização. Considerando-se a importância da temática e necessidade de novos estudos sobre a questão, este estudo foi proposto com o objetivo de analisar a eficácia da técnica de Cloze num programa de desenvolvimento da compreensão em leitura com alunos de $5^{\mathrm{a}}$ série do ensino fundamental.

\section{MÉTODO}

\section{Participantes}

Participaram 24 alunos de $5^{\text {a }}$ série de uma escola pública do interior de São Paulo. Do total, 11 eram do gênero masculino $(45,8 \%)$ e 13 do feminino $(54,2 \%)$. A média de idade foi de 11,8 anos, variando de 11 a 13 anos e desvio padrão de 0,74 .

\section{Material}

Além do questionário de caracterização, com itens referentes à identificação do aluno e informações sobre seus hábitos e dificuldades de leitura e estudo, foram utilizados textos estruturados em diferentes modalidades da técnica de Cloze. A criação das lacunas seguiu sempre o esquema de razão, independentemente da categoria gramatical dos vocábulos. Tais textos foram retirados de livros de Língua Portuguesa para a $5^{\mathrm{a}}$ série. No pré e pós-testes os trechos utilizados foram organizados no padrão de Cloze tradicional com o quinto vocábulo omitido, visando o diagnóstico da compreensão em leitura. Nas demais etapas do programa os trechos foram elaborados com a omissão do décimo vocábulo, introduzindo dificuldades crescentes para o seu preenchimento, com folhas de instrução adequadas a cada uma das modalidades, descritos no procedimento a seguir.

\section{Procedimento}

Este estudo foi desenvolvido durante dois meses, como parte de um estudo mais amplo, e envolvia a participação de vários auxiliares de pesquisa, especialmente treinados para a tarefa. As sessões eram semanais e ocorriam sempre nas aulas de Língua Portuguesa, contando com a colaboração das professoras das turmas.

Após a explicação dos objetivos do trabalho e a concordância de participação dos alunos, o desenvolvimento do programa ocorreu em oito sessões semanais. A primeira incluiu a aplicação de um questionário de caracterização e a aplicação do teste de Cloze, como pré-teste, distribuído juntamente com uma folha de instrução, que trazia uma frase para treinamento.

O programa propriamente dito foi desenvolvido em seis semanas, seguindo um padrão semelhante em todas as sessões. Assim, utilizou-se em todas elas um texto com o décimo vocábulo omitido, sendo as instruções eram lidas em voz alta. Era dado o tempo necessário para o preenchimento do texto e a correção imediata era feita pelos próprios alunos, com base na leitura do texto completo pela aplicadora. Os textos em Cloze diferenciaram-se em dificuldades gradualmente inseridas nas aplicações subseqüentes, tal como especificado a seguir. No primeiro texto das sessões do programa forneceu-se aos alunos duas alternativas de respostas, apresentadas sob cada lacuna. No segundo, houve o oferecimento de três alternativas de respostas, apresentadas sob cada uma das lacunas. No 
terceiro texto utilizou-se a técnica do Cloze limitado, no qual todas as palavras retiradas do texto foram elencadas em folha à parte, em ordem aleatória. No quarto texto apenas a primeira letra de cada palavra constava nos traços de cada lacuna. $\mathrm{O}$ quinto texto incluiu um tracejado com o número exato de letras que cada uma das palavras omitidas continha. No sexto e último texto, nenhuma pista adicional era fornecida, havendo apenas a omissão dos décimos vocábulos, substituídos por um traço proporcional ao tamanho da palavra retirada.

O programa de intervenção incluiu ainda a aplicação do pós-teste. Nesta sessão o texto foi organizado novamente dentro dos padrões tradicionais do Cloze com o $5^{\circ}$ vocábulo omitido. Vale ressaltar que nas sessões de pré e pós-teste não foram os alunos que corrigiram seus textos e que não lhes foi dado feedback imediato. O critério de correção implicou na atribuição de um ponto para cada acerto, cuja soma foi transformada em porcentagem, pois em cada texto havia um número diferente de lacunas a serem completadas.
Os dados foram submetidos a provas de estatística descritiva, visando a caracterização dos participantes no que se refere aos hábitos de leitura. Assim, verificou-se que a prática de leitura entre os alunos é baixa, sendo que 6 alunos (25\%) responderam que liam um livro por mês e 9 (37,5\%) não responderam a questão. Ao se perguntar sobre o gênero de leitura que escolhiam, 17 alunos (71\%) assinalaram "livros de estudo". Quanto à persistência na leitura, verificou-se que ela era muito baixa, visto que a maioria dos alunos $(\mathrm{N}=19 ; 79 \%)$ afirmava que parava de ler, antes de chegar ao final do livro. As respostas à questão que investigava quais as principais fontes de incentivo à leitura apontaram para a professora em primeiro lugar $(\mathrm{N}=16 ; 67 \%)$, e para a mãe em segundo lugar $(\mathrm{N}=13$; $54 \%)$.

Para computar-se o nível de compreensão em leitura os alunos foram categorizados, considerando-se a classificação de Bormuth (1968), segundo a qual o percentual de até $40 \%$ de acerto no teste de Cloze corresponde ao nível de frustração; de 41 a $56 \%$ ao nível instrucional e de $57 \%$ ou acima, ao nível independente. A Tabela 1 ilustra a média percentual de acertos obtido pelos participantes em cada uma das sessões do programa.

\section{RESULTADOS}

\begin{tabular}{lc}
$\begin{array}{l}\text { Tabela 1: Porcentagem média de acerto em cada } \\
\text { sessão }(N=24)\end{array}$ \\
\hline Sessões & Porcentagem média de acerto \\
\hline Pré-teste & 21,83 \\
Treino 1 & 80,17 \\
Treino 2 & 87,04 \\
Treino 3 & 75,83 \\
Treino 4 & 64,17 \\
Treino 5 & 47,12 \\
Treino 6 & 47,79 \\
\hline Pós-teste & 48,38 \\
\hline
\end{tabular}

Considerando-se que os grupos eram pequenos, os instrumentos utilizados não eram testes padronizados para a população em geral e que as medidas eram de nível ordinal, optou-se pelo uso de testes estatísticos não paramétricos (Siegel, 1956). Assim, para se avaliar as correlações entre os desempenhos ao longo do programa recorreu-se à prova de correlação de Spearman . Os dados obtidos estão apresentados na Tabela 2.

Tabela 2: Índices de correlação obtidas entre as diferentes etapas do programa

\begin{tabular}{|c|c|c|c|c|c|c|c|c|}
\hline Etapas & & Pré-teste & Treino 1 & Treino 2 & Treino 3 & Treino 4 & Treino 5 & Treino 6 \\
\hline \multirow[t]{2}{*}{ Treino 1} & $r$ & 0,380 & & & & & & \\
\hline & $p$ & 0,067 & & & & & & \\
\hline
\end{tabular}




\begin{tabular}{lllllllll} 
Treino 2 & $\mathrm{r}$ & 0,244 & 0,247 & & & & \\
& $\mathrm{p}$ & 0,251 & 0,245 & & & & \\
Treino 3 & $\mathrm{r}$ & 0,044 & $\mathbf{0 , 4 2 2}$ & 0,164 & & & \\
& $\mathrm{p}$ & 0,837 & $\mathbf{0 , 0 4 0}$ & 0,445 &. & & & \\
Treino 4 & $\mathrm{r}$ & 0,185 & 0,292 & $\mathbf{0 , 6 6 8}$ & $\mathbf{0 , 4 7 7}$ & & & \\
& $\mathrm{p}$ & 0,386 & 0,166 & $\mathbf{0 , 0 0 0}$ & $\mathbf{0 , 0 1 8}$ & & & \\
Treino 5 & $\mathrm{r}$ & $-0,055$ & 0,127 & 0,277 & $\mathbf{0 , 5 1 2}$ & $\mathbf{0 , 4 7 2}$ & & \\
& $\mathrm{p}$ & 0,799 & 0,553 & 0,190 & $\mathbf{0 , 0 1 1}$ & $\mathbf{0 , 0 2 0}$ & & \\
Treino 6 & $\mathrm{r}$ & $-0,127$ & 0,226 & 0,282 & 0,458 & 0,314 & $\mathbf{0 , 8 7 1}$ & \\
& $\mathrm{p}$ & 0,554 & 0,289 & 0,182 & 0,025 & 0,135 & $\mathbf{0 , 0 0 0}$ & \\
Pós-teste & $\mathrm{r}$ & $-0,139$ & 0,198 & 0,225 & 0,356 & $\mathbf{0 , 4 4 6}$ & $\mathbf{0 , 4 2 6}$ & $\mathbf{0 , 4 0 5}$ \\
& $\mathrm{p}$ & 0,516 & 0,354 & 0,290 & 0,088 & $\mathbf{0 , 0 2 9}$ & $\mathbf{0 , 0 3 8}$ & $\mathbf{0 , 0 5 0}$ \\
\hline
\end{tabular}

Nível de significância: $p \leq 0,05$

Verificou-se que alguns índices de correlação positiva foram estatisticamente significativos entre as pontuações obtidas nas diferentes etapas do programa. Além disso, foram detectados índices de correlação negativa, mas sem significância estatística, entre o pré-teste e o treino 5 e 6 , bem como com o pré-teste. Tal resultado parece coerente com a esperada melhora de desempenho ocorrida ao longo do programa.
Para efeito de comparação, cada aluno foi categorizado no pré e pós-testes nos níveis definidos por Bormuth (1968). No pré-teste todos os alunos ficaram no nível de frustração, ou seja, nenhum deles atingiu mais do que $40 \%$ de acertos no teste de Cloze aplicado. No entanto, após o término do programa e baseado no resultado do pós-teste, cada aluno foi novamente categorizado nos diferentes níveis e as mudanças ocorridas aparecem na Figura 1.

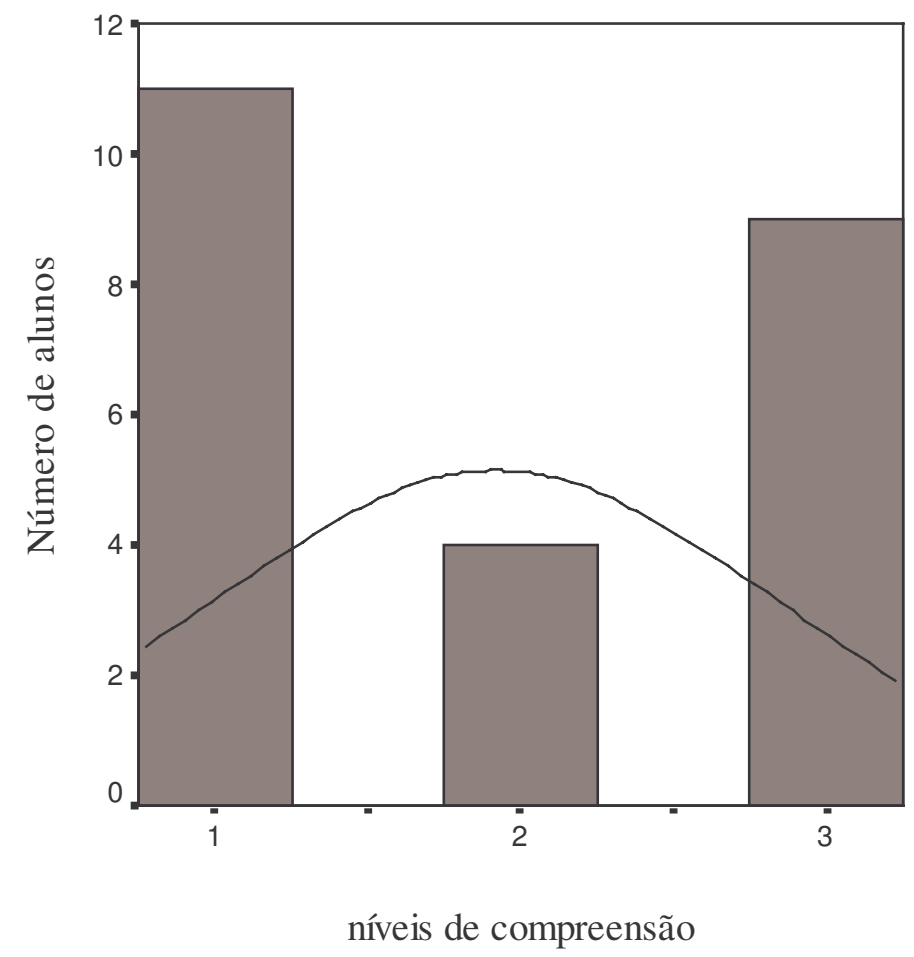

Figura 1: Distribuição dos alunos nos diversos níveis de compreensão após o programa de remediação (nível 1= frustração; nível $2=$ instrucional; nível $3=$ independência)

Os dados revelam que dos 24 alunos que participaram do programa de remediação, 11 continuaram no nível de frustração, ou seja, no pós-teste não apresentaram progressos suficientes para que mudassem de 
nível. No entanto, houve quatro alunos que passaram para o nível instrucional e 10 alunos saltaram do nível de frustração para o nível independente de leitura.

Para a comparação dos efeitos do programa de remediação no grupo como um todo, utilizou-se o teste de Wilcoxon para amostras independentes, impondose como nível de significância $p \leq 0,02$. Tal decisão visou assegurar um maior rigor para a eventual generalização dos resultados.

A análise demonstrou que o programa foi eficaz para o desenvolvimento da compreensão em leitura, visto que houve diferença estatisticamente significativa entre o percentual de acerto obtido entre o pré e o pós-teste. Assim, verificou-se que com $N=24$, o $\mathrm{T}_{\mathrm{c}}$ ficou estabelecido em 81 e o $T_{0}$ foi de 13 , sendo $Z=-$ 3,879 e $p \leq 0.001$.

\section{DISCUSSÃO}

Pelos dados obtidos com a aplicação do questionário de caracterização foi possível verificar-se a baixa freqüência de leitura entre os alunos. Tal fato também é apontado em vários estudos que investigaram a questão. Nesse sentido, há referências explícitas sobre o quadro desalentador da realidade brasileira, fruto de uma ausência de políticas públicas que deveriam favorecer o desenvolvimento do estudante como leitor (Silva, 1983; Matos, 2001; Zucoloto, 2001).

Acrescenta-se, ainda, que os alunos apontaram como gênero de leitura mais lido os "livros de estudo", demonstrando que identificaram o comportamento de ler com o de estudar. Assim, a leitura é vista apenas como obrigação e não uma opção pessoal. Resultados semelhantes foram encontrados em outros estudos como os de Marini (1980) e Di Nucci (2002). Tal fato, infelizmente não se modifica em etapas mais avançadas de escolarização, pois é muito similar quando a população estudada é de universitários (Marini, 1986; Santos, 1990; Oliveira, 1999; Santos, Suehiro \& Oliveira, 2004).

É importante destacar o papel da escola e da família no incentivo à leitura, visto que são citadas as professoras e as mães como as pessoas que mais estimulam o aluno para ler. A literatura tem apontado a importância da motivação para a leitura em todas as etapas de escolarização, mostrando que quanto mais precoce for a percepção sobre o prazer resultante dela, mais chances há de que o comportamento de ler se torne mais freqüente (Viessi, 1979; Braga, 1981; Manna \& Misheff, 1987; Pellegrini, Santos \& Sisto, 2002).

Vários são os estudos que demonstram, por um lado, a importância de se envolver os pais numa necessária parceria com a escola, favorecendo práticas de letramento que, dessa forma, ocorreriam de forma natural no dia a dia das crianças. Por outro lado, a leitura de histórias infantis, tanto pela professora, como pelos pais são importantes para despertar o interesse da criança pela leitura, como apresentam relação direta com o êxito escolar (Leichter, 1984; Morrow, 1995; Santos \& Joly, 1996; Di Nucci, 1997; Corrêa, 2001).

Os baixos resultados obtidos pelos alunos com o uso da técnica de Cloze, detectados no pré-teste, reafirmam a eficácia da técnica como diagnóstico da compreensão em leitura. Da mesma forma, em diferentes contextos, estudiosos da área empregaram-na com objetivos de identificar dificuldades de leitura de textos. Subjacente ao seu uso está a visão da compreensão como um processo interativo entre o leitor e o escritor do texto, salientando a importância da percep- 
ção das pistas gramaticais e semânticas nele contidas, bem como do conhecimento prévio sobre o assunto (Marini, 1980; Santos, 1981; Giordano, 1985; Bitar, 1989; Kobayashi, 2002).

Ao se analisar os índices de correlação obtidos nas diversas sessões do programa, algumas considerações importantes devem ser feitas. As porcentagens de acerto foram maiores nas primeiras sessões, pois a exigência é bastante reduzida nas modalidades empregadas. As alternativas estavam disponíveis e bastava que o aluno identificasse a resposta correta (Cloze de múltipla escolha e Cloze limitado). Posteriormente foi necessário que o aluno descobrisse qual era a resposta adequada e, mesmo havendo pistas explícitas, era necessário que ele recorresse ao conhecimento prévio e ao contexto para descobrir a palavra que melhor completava o sentido do texto. Isto parece explicar a ausência de índices de correlação significativa entre os resultados das primeiras sessões com as últimas, bem como a identificação de índices de correlação positiva entre os resultados das últimas sessões e do pós-teste. Resultados similares foram obtidos em outros estudos, envolvendo a aplicação do Cloze gradual em programas de remediação de leitura (Hines \& Warren, 1978; Grant, 1979; Porter, 1979; Braga, 1981).

De qualquer modo, os resultados promissores alcançados com o uso da técnica no programa de intervenção implementado, também são coerentes com estudos que têm sido divulgados no Brasil. Vários pesquisadores ressaltam que, por meio do procedimento de Cloze, pode-se dinamizar o processo de compreensão, enriquecer o vocabulário infantil e favorecer o processo de aprendizagem, independentemente do conteúdo (Carelli, 1992; Castelo Branco, 1992; Neves, 1997; Bampi, 2000).

\section{CONSIDERAÇÕES FINAIS}

A técnica de Cloze com suas inúmeras possibilidades de variações favorece sua utilização com textos de diferentes conteúdos, sejam específicos e ligados a disciplinas escolares, sejam de caráter literário, como os utilizados no presente estudo. Os vocábulos podem ser omitidos em função do objetivo pretendido, visando a verificação da legibilidade do texto ou a avaliação das dificuldades de compreensão dos alunos. É fato costumeiramente destacado sua facilidade de elaboração e correção, além do baixo custo, o que torna viável sua utilização em sala de aula.

Vale lembrar ainda que seu emprego favorece o desenvolvimento da compreensão da leitura, auxiliando o aluno a estabelecer relações entre os elementos do texto, recorrer ao conhecimento anteriormente aprendido e o conhecimento novo trazido no texto que está sendo lido. Ao lado disso, permite também que o aluno reconheça o quanto está ou não compreendendo. Dessa forma, torna-se um instrumento poderoso para o emprego de estratégias metacognitivas de monitoração da própria compreensão.

As vantagens e limitações deste estudo estão relacionadas com o seu emprego na situação de sala de aula, importantes para possibilitar a viabilidade da transformação mais imediata dos resultados das pesquisas em práticas educativas. Assim, por um lado, demonstra a possibilidade de se fazer pesquisa em situação natural, com a colaboração da professora, que aprende e se interessa pela utilização de novos recursos. Por outro lado, traz as implicações relacionadas ao controle da situação, especialmente quando se trabalha com adolescentes.

Finalmente, destaca-se a necessidade de se utilizar várias estratégias motivacionais, que demonstrem o valor da leitura, para que os alunos nessa faixa etária se engajem na atividade com empenho e disposição para aprender. Apesar das dificuldades, sugere-se que estudos similares sejam realizados em outras séries e em escolas diferentes para que a ampliação do conhecimento e a estabilidade dos dados obtidos permitam a generalização dos resultados e sua aplicação mais ampla como estratégia de ensino.

\section{REFERÊNCIAS}

Abraham, R. G. \& Chapelle, C. A. (1992). The meaning of Cloze test scores: An item difficulty perspective. The Modern Language Journal, 76, 468-479.

Ashby-Davis, C. (1985). Cloze and reading comprehension: A qualitative analysis and critique. Journal of Reading, 28, 7, 585589.

Bampi, M. L. F. (2000). Programa para o desenvolvimento da leitura e escrita: faz-de-conta e criatividade. Tese de Doutorado. Instituto de Psicologia da USP, São Paulo-SP.

Bitar, M. L. (1989). Eficiência dos instrumentos de avaliação em leitura. Dissertação de Mestrado. Pontifícia Universidade Católica de São Paulo, São Paulo-SP.

Bormuth, J. R. (1968). Cloze Test Readability: Criteria Reference Score. Journal Educational Measurement, 5, 189-196.

Boruchovitch, E. (1999). Estratégias de aprendizagem e desempenho escolar: considerações para a prática educacional. Psicologia Reflexão e Crítica, 12(2), 361-376.

Braga, S. M. L (1981). Remediação da leitura: um estudo com escolares de primeiro grau utilizando a técnica de Cloze. Dissertação de Mestrado. Instituto de Psicologia da USP, São Paulo.

Carelli, A. E. (1992). Teste da eficiência de programas em compreensão e leitura crítica. Dissertação de Mestrado. Pontifícia Universidade Católica de Campinas. Campinas-SP.

Castelo Branco, S. M. C. (1992). Estudo do desenvolvimento de leitura oral em escolares de $1^{a}$ a $4^{a}$ série do primeiro grau. Dissertação de Mestrado. Pontifícia Universidade Católica de São Paulo, São Paulo-SP.

Corrêa, M. L. G. (2001). Letramento e heterogeneidade da escrita no ensino de Língua Portuguesa. Em I. Signorini (Org.), Investigando a relação oral/escrito e as teorias do letramento (p.p. 135-166). Campinas: Mercado de Letras. 
Di Nucci, E. P. (1997). Interesses e dificuldades dos pais na alfabetização dos filhos. Psicologia Escolar e Educacional, 1(2/3), 23-28.

Di Nucci, E. P. (2002). Letramento: Algumas práticas de leitura do jovem do ensino médio. Psicologia Escolar e Educacional, 6(1), 32-38.

Galinkoff, R. M. (1975-76). Comprehension in good and poor readers. Reading Research Quarterly, 11(3), 624-659.

Giordano, G. (1985). Learning to reading erased text. Academic Therapy, 20(8), 317-322.

Granja, E. C. (1985). Contribuições ao estudo da leitura entre universitários. Dissertação de Mestrado. Instituto de Psicologia da USP, São Paulo-SP.

Grant, P. L. (1979). The Cloze procedure as an instuctional device. Journal of Reading, 28(4), 719-705.

Helfeldt, J. P. \& Henk, W.A. (1985). Usefulness of conventional vs total random cued cloze tests as measure of reading comprehension. Journal of Reading, 28(8), 719-725.

Hines, T.C. \& Warren, J. (1978). A computadorized technique for producing Cloze test material. Educational Technology, 18(9), 56-58.

Kobayashi, M. (2002). Cloze tests revisited: Exploring item characteristics with special attention to scoring methods. Modern Language Journal, 86(4), 571-586.

Leichter, H. J. (1984). Families as environments for literacy. Em H. Goelman; A. Oberg \& F. Smith (Orgs.), Awaking to literacy (pp. 39-51). Portsmouth-NH: Heinemann Educational Books.

Lopes, M. M. L. (1981). O hábito de leitura em escolares do $2^{\circ}$ grau freqüentadores e não freqüentadores da biblioteca pública. Dissertação de Mestrado. Universidade Federal da Paraíba. João Pessoa-PB.

Manna, A. \& Misheff, S. (1987). What teachers say about their own reading development. Journal of Reading, 31(2), 160-168.

Marini, A. (1980). Remediação de leitura e intelegibilidade de textos: estudos contrastivos. Dissertação de Mestrado. Instituto de Psicologia da USP, São Paulo-SP.

Matos, H. A. V. (2001). O texto e a produção da leitura na escola: novos rumos e desafios. Em S. A. S. Leite (Org.), Alfabetização e letramento: contribuições para as práticas pedagógicas (pp. 155-183). Campinas: Komedi-Arte Escrita.

Mello, M. T. P. (1986). Estudo psicolingüístico de dois materiais de leitura de história do brasil, quanto aos aspectos vocabular e figurativo. Tese de doutorado. Faculdade de Filosofia, Letras e Ciências Humanas da USP, São Paulo-SP.

Molina, O. (1979). Avaliação da inteligibilidade de livros didáticos de $1^{o}$ e $2^{o}$ graus por meio da técnica de Cloze. Tese de Doutorado. Instituto de Psicologia da USP, São Paulo-SP.

Morrow, L. M. (1995). (Org.). Family literacy: connections in school and communities. Newark-DE: International Reading Association.

Muth, K. D. (1989). Children's comprehension of text. NewarkDE: International Reading Association.

Neves, T. R. P. (1997). O processamento da informação na leitura de textos em sala de aula. Dissertação de Mestrado. Universidade Federal de Santa Maria, Santa Maria-RS.
Oliveira, M.H.M.A. (1999). Comportamento de leitura do estudante universitário. Em G.P. Witter (Org.), Leitura: textos e pesquisas (pp. 125-139). Campinas: Alínea.

Olson, M. W. (1990). Opening the door to classroon research. Newark-DE: International Reading Association.

Pellegrini, M. C. K, Santos, A. A. A. \& Sisto, F. F. (2002). Evaluación de las actitudes de lectura en universitarios. Buenos Aires: Lectura y Vida, 23(2), 26-33.

Poersch, J. M. (1993). Pontos de convergência entre leitura $e$ escritura. Porto Alegre: EDIPUCRS.

Porter, D. (1979). Cloze procedure and equivalence. Language Learning, 28(2), 333-341.

Riley, J. D. (1986). Progressive Cloze as a remedial technique. The Reading Teacher, 39(6), 576-581.

Santos, A. A. A. \& Joly, M. C. R. A. (1996). Lendo Histórias em Família: Influência sobre o Vocabulário Infantil. Psicologia Escolar e Educacional, 1(1) 39-44.

Santos, A. A. A. (1981). Desenvolvimento do hábito de leitura e compreensão de textos através da aplicação de fichas: um estudo com adolescentes carentes. Dissertação de mestrado. Pontifícia Universidade Católica de Campinas, Campinas-SP.

Santos, A. A. A. (1990). Compreensão em leitura na universidade: um estudo comparativo entre dois procedimentos de treino. Estudos de Psicologia, 7(2), 39-53.

Santos, A. A. A.; Suehiro, A. C. B. \& Oliveira, K. L. (2004). Habilidades em compreensão da leitura: um estudo com alunos de psicologia. Estudos de Psicologia, 21(2), 29-42.

Sasaki, M. (2000). Effects of cultural schemata on students' testtaking processes for cloze tests: A multiple data source approach. Language Testing, 17(1), 85-114

Siegel, S. (1956). Non-parametric statistics for the behavioral science. New York: McGraw Hill. Tradução para McGraw Hill do Brasil em 1977.

Silva, E. T. (1983). Leitura e realidade brasileira. Porto Alegre: Mercado Aberto.

Söhnhen, C. B. C (1998).O procedimento de “cloze" como o indicador de conhecimento prévio. Dissertação de mestrado. Pontifícia Universidade Católica do Rio Grande do Sul, Porto Alegre-RS.

Taylor, W. L. (1953). Cloze Procedure: A new tool for measuring readability. Journalism Quarterly, 30, 415-433.

Viessi, V. R. (1979). Sistema contratual para leitores relutantes: um estudo com escolares de $1^{o}$ grau. Tese de doutorado. Instituto de Psicologia da USP, São Paulo-SP.

Witter, G.P. (1978). Efeito de dois parâmetros do procedimento de Cloze. Arquivo Brasileiro de Psicologia Aplicada, 9(10), 4-9.

Zucoloto, K.A. (2001). A compreensão da leitura em crianças com dificuldade de aprendizagem em escrita. Dissertação de Mestrado. Faculdade de Educação da UNICAMP, CampinasSP.

Enviado: 09/10/2004 Revisado: $15 / 11 / 2004$ Aceito: $17 / 11 / 2004$

\section{Sobre a autora:}


Acácia Aparecida Angeli dos Santos: Psicóloga pela PUC-Campinas. Doutora em Psicologia Escolar e do Desenvolvimento Humano pela Universidade de São Paulo. Docente da graduação e do Programa de Pós-Graduação stricto sensu em Psicologia da Universidade de São Francisco - Itatiba-SP. Endereço Eletrônico: acaciasantos@ terra.com.br. 